\title{
A Thiamine Responsive Megaloblastic Anemia Presented with Hypertriglyceridemia and Auto- immune Diabetes
}

\author{
One Sentence Summary: Thiamine therapy might be an alternative in patients \\ presenting with diabetes and anemia.
}

Authors

Affiliations

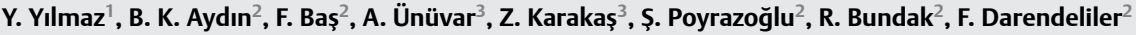

Affiliation addresses are listed at the end of the article

\author{
Key words \\ - thiamine responsive \\ megaloblastic anemia \\ - diabetes mellitus \\ - hypertriglyceridemia
}

\begin{abstract}
Background: Thiamine responsive megaloblastic anemia syndrome (TRMA) is an autosomal recessive disorder characterized by non type 1 diabetes mellitus (DM), sensorineural hearing loss and megaloblastic anemia and caused by mutations in SLC19A2 gene, encoding a thiamine transporter protein.

Case: A 3-month-old male infant presented with megaloblastic anemia, DM, patent ductus arteriosus and hypertriglyceridemia. His auto-
\end{abstract}

\section{Introduction}

$\nabla$

received 20.11.2014

first decision 15.03.2015

accepted $\quad 08.04 .2015$

\section{Bibliography}

DOI http://dx.doi.org/ 10.1055/s-0035-1549874

Exp Clin Endocrinol Diabetes

Rep 2015; 2: e8-e10

(c) ]. A. Barth Verlag in Georg Thieme Verlag KG Stuttgart · New York ISSN 2196-7407

\section{Correspondence}

\section{Yasin YIImaz, MD}

Department of Pediatrics Istanbul University Istanbul Medical Faculty

Millet Cad, 34093 Fatih/

İstanbul

Istanbul

Turkey 34093

Tel.: + 90/212/4142 200/3-1238

dryasinyilmaz@gmail.com

\section{License terms}

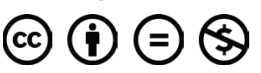

Thiamine-responsive megaloblastic anemia syndrome (TRMA) or Rogers' syndrome (OMIM 249270) is an autosomal recessive disorder whereby active thiamine uptake into cells is disturbed and is characterized by the triad of anemia, non type 1 diabetes mellitus (DM) and sensorineural deafness. In addition, optic atrophy, retinal involvement [1], congenital heart defects [2], stroke [3], pancytopenia and severe psychosis [4] have also been described in patients with TRMA. Although the syndrome was first described by Rogers in 1969 [5], SLC19A2, the gene encoding a high-affinity thiamine transporter protein (THTR-1), was identified in 1999 [6]. This gene is expressed in a wide range of human tissues including bone marrow, pancreas, brain, retina, heart, skeletal muscle, kidney, liver, lung, small intestine, colon, placenta, lymphocytes, and fibroblasts [7].

Hypertriglyceridemia in children is rarely seen and maybe hereditary or secondary to DM [8]. Monogenic disorders usually result from loss of function mutations in the genes lipoprotein lipase (LPL) or apolipoprotein C2 (APOC2) [9]. Anemia during childhood is not rare and nearly $20 \%$ of American children have anemia during immune markers for DM were positive but with the additional finding of sensorineural deafness he was diagnosed with TRMA and thiamine therapy was started. His anemia was improved and insulin needs decreased and his genetic studies revealed a homozygous frameshift mutation, c.641del within coding region of SLC19A2 gene.

Conclusion: Clinical presentation of TRMA could be highly variable and some co-existence could perplex physicians, but this diagnosis should be considered in all patients with DM and anemia and further assessment should be done. their childhood [10]. Evaluation of anemia is usually based on mean corpuscular volume and severe anemia warrants further investigations [11].

Here, we report a 3-month-old male infant who presented with anemia, autoantibody positive DM and hypertriglyceridemia and was diagnosed with TRMA by indicating SLC19A2 gene mutation.

\section{Case Report \\ $\nabla$}

A 3-month-old male infant presented to our outpatient clinic with weakness and pallor. He was born as the first child of healthy first degree consanguineous parents at term, after an uneventful pregnancy with normal birth weight. His physical examination revealed tachycardia, grade $2 / 6$ continuous murmur and a palpable hepatomegaly of $2 \mathrm{~cm}$ below the right subcostal margin. His weight was $5270 \mathrm{~g}(-1.27 \mathrm{SDS})$, height was $59 \mathrm{~cm}$ $(-0.85$ SDS $)$, and head circumference was $38.2 \mathrm{~cm}(-2.14$ SDS). Laboratory analyses showed severe anemia with a hemoglobin level of $6.9 \mathrm{~g} / \mathrm{dL}$, hematocrit $16.9 \%$, mean corpuscular volume $89 \mathrm{fL}$, white blood cell count $9900 / \mathrm{mm}^{3}$, and platelets $251000 / \mathrm{mm}^{3}$. The reticulocyte 
count was $0.1 \%$. The peripheral blood smear revealed poikilocytosis, polychromasia, microcytic hypochromic erythrocytes without atypical cells. Ferritin, folic acid and vitamin B12 were all in normal limits. Viral serology was negative. Red blood cell transfusion was done. Examination of his bone marrow aspirate demonstrated increased megaloblastic erythropoiesis and megakaryopoiesis.

At his first presentation his blood samples, drawn for the laboratory analysis were white colored and serum biochemistry revealed hypertriglyceridemia (triglyceride $951 \mathrm{mg} / \mathrm{dL}$ ). His total cholesterol level was $140 \mathrm{mg} / \mathrm{dL}$ at that time and after 1 week HDL cholesterol $16 \mathrm{mg} / \mathrm{dL}$ and LDL cholesterol $78 \mathrm{mg} / \mathrm{dL}$ while triglyceride was $257 \mathrm{mg} / \mathrm{dl}$. For differential diagnosis of hypertriglyceridemia, fresh frozen plasma was given to infant and patient was accepted as responsive due to the decrease of triglyceride level $(416 \mathrm{mg} / \mathrm{dL})$. Therefore, condition was accepted as APOC2 deficiency and special formula and medium-chain fatty acids were ordered. With those therapies his triglyceride levels were improved gradually and after 6 months his diet therapy was stopped. His parent's lipid profiles were normal.

In addition to his anemia and hypertriglyceridemia, his serum glucose level was very high (glucose $404 \mathrm{mg} / \mathrm{dL}$ ) at initial presentation. Blood gas analysis and other biochemistry were normal. HbA1c was high (7.2\%), insulin and C-peptide levels were low with respect to his very high blood glucose level $(3.0 \mu \mathrm{IU} / \mathrm{mL}$ and $1.14 \mathrm{ng} / \mathrm{mL}$, respectively). But C-peptide level with glukagon stimulation was normal (glucose $124 \mathrm{mg} / \mathrm{dL}$, C-peptide $2.36 \mathrm{ng} /$ $\mathrm{mL}$ ). Subcutaneous insulin therapy was started because of the high glucose levels at the follow-up. His glutamic acid decarboxylase antibody (Anti-GAD) was found to be negative $[0.22 \mathrm{U} / \mathrm{mL}$ (normal: <1)], but anti insulin antibody (AIA) and islet cell antibody were positive $[2.47 \mathrm{U} / \mathrm{mL}$ (normal: $<0.4$ ) and $39 \mathrm{JDFu}$ (normal: <10), respectively].

His echocardiography revealed small patent ductus arteriosus (PDA). Abdominal ultrasonography showed grade 1 hepatosteatosis. Bilateral sensorineural hearing loss was detected and the patient was referred to an otolaryngologist for evaluation for hearing device implantation. His ophthalmologic examination revealed macular scars of retina, but his optic nerves were normal.

The findings of macrocytic anemia, sensorineural hearing loss and DM led us to consider a presumptive diagnosis of TRMA, and oral thiamine therapy with a dose of $100 \mathrm{mg}$ /day was started. Hemoglobin level increased gradually and was $12.3 \mathrm{mg} / \mathrm{dL}$ at the end of second week on thiamine therapy. Insulin doses could be reduced but insulin therapy could not be ceased totally. The diagnosis of TRMA was confirmed by sequence analysis of coding and flanking intronic regions of the SLC18A2 gene, which showed a homozygous frameshift mutation, c.641del in exon 2. This mutation was a deletion of a $G$ nucleotide at position 641 (c.641delG) which was predicted to result in premature termination at codon 227 (p.S214fsX14). His father and mother were heterozygous for this mutation. (Peninsula Medical School, Exeter, United Kingdom).

At the last follow-up visit he was 4 years and 8 months old and his height was $116.7 \mathrm{~cm}$ (1.88 SDS), his weight was $20.7 \mathrm{~kg}$ ( 0.99 SDS). He was on multiple dose daily insulin $(0.7 \mathrm{U} / \mathrm{kg} /$ day $)$ and thiamine $(100 \mathrm{mg} /$ day $)$ therapy. His HbA1c was $7.4 \%$ and his lipid profile was normal. PDA was closed spontaneously but first degree atrioventricular block was detected on his routine cardiologic evaluation. Hepatic steatosis resolved completely, as estimated by ultrasonography.

\section{Discussion}

$\nabla$

DM in infancy is very rare and usually caused by single gene mutations $[12,13]$. DM in TRMA is due to a non-autoimmune mechanism and is most likely secondary to impairment of islet cell function caused by intracellular thiamine deficiency [14]. Thiamine and TMP/TPP transporters may have abnormal expression in diabetes. Increased THTR1 levels were found in red blood cells (RBCs) and mononuclear leucocytes of patients with diabetes [15]. There might be different responses of THTR1 expression in different cell types in diabetes: RBC precursors and leucocytes appeared to upregulate THTR1 expression in response to decreased thiamine availability, whereas renal tubular epithelial cells have decreased expression [16].

DM usually develops in early childhood in TRMA and the response to thiamine supplementation is variable [17]. Insulin could be stopped at the beginning of thiamine therapy, but required in addition to thiamine supplementation after puberty in most of the patients [18]. The classical hematological finding of TRMA is megaloblastic anemia and can be explained by the role of thiamine in DNA metabolism and heme synthesis. In a study with 13 TRMA patients, Ricketts et. al [18] has shown that the anemia and DM responded to oral thiamine hydrochloride, but during puberty thiamine supplements became ineffective, and almost all patients require insulin therapy and regular blood transfusions in adulthood. All patients that Ricketts et al. reported were homozygous for mutations in the SLC19A2 gene. Although our patient did not need any red blood cell transfusion after thiamine supplementation, his insulin requirement continued. Because of the positive autoantibodies an additional autoimmune process is suspected, but his young age at the time of autoantibody investigation make the results unreliable and so it is not clear whether this finding is due to the type of his mutation or to an additional autoimmune process.

Crouzet-Ozenda Luci et al. [19] were first to show a co-existence of metabolic disease with TRMA. They reported an infant followed with the diagnosis of congenital galactosemia since the age of 8 days, diagnosed with TRMA at the age of 10 months. In our patient, severe hypertriglyceridemia was detected at admission. For the differential diagnosis, fresh frozen plasma was given and with the good response to this treatment he was accepted as APO C2 enzyme deficient and special treatment ordered. In his follow-up, triglyceride levels decreased dramatically and at the end of 6 months, special formula was ceased and breastfeeding continued. His hypertriglyceridemia was considered as a consequence of his DM. Marked elevations in the levels of triglycerides can be seen in poorly controlled type $1 \mathrm{DM}$ because of a reduction in the activity of LPL. LPL is an insulin regulated enzyme, synthesized in adipose tissue and muscle, and hydrolyzes triglycerides in the core of chylomicrons and VLDL [20].

In conclusion, clinical presentation of TRMA could be highly variable and some co-existence could perplex physicians, but this diagnosis should be considered in all patients with DM and anemia. In patients with the diagnosis of TRMA cardiovascular evaluation should be done at the follow-up period in addition to hematology, endocrinology, otolaryngology, ophthalmology assessments, even if they did not have any cardiac manifestations before the thiamine therapy. 


\section{Acknowledgments}

The authors are grateful to Sarah Flanagan and Sian Ellard (Peninsula Medical School, Exeter, United Kingdom) for performing genetic testing of the patient.

\section{Conflict of interest: None.}

\section{Affiliations}

${ }^{1}$ Department of Pediatrics, Istanbul University Istanbul Medical Faculty, Istanbul, Turkey

${ }^{2}$ Department of Pediatrics, Division of Growth-Development, Pediatric Endocrinology and Diabetes, Istanbul University Istanbul Medical Faculty, Istanbul, Turkey

Department of Pediatrics, Division of Hematology and Oncology, Istanbul University, Istanbul Medical Faculty, Istanbul, Turkey

\section{References}

1 Meire FM, Van Genderen MM, Lemmens K, Ens-Dokkum MH. Thiamineresponsive megaloblastic anaemia syndrome (TRMA) with cone-rod dystrophy. Ophthalmic Genet 2000; 21: 243-250

2 Lorber A, Gazit AZ, Khoury A, Schwartz Y, Mandel H. Cardiac manifestations in thiamine-responsive megaloblastic anaemia syndrome. Paediatric Cardiology 2003; 24: 476-481

3 Villa V, Rivellese A, Di Salle F, Iovine C, Poggi V, Capaldo B. Acute ischemic stroke in a young woman with the thiamineresponsive megaloblastic anaemia syndrome. J Clin Endocrinol Metab 2000; 85: 947-949

4 Lagarde WH, Underwood LE, Moats-Staats BM, Calikoglu AS. Novel mutation in the SLC19A2 gene in an African-American female with thiamine- responsive anemia syndrome. Am J Med Genetics 2004; 125A: 299-305

5 Porter FS, Rogers LE, Sidbury JB Jr. Thiamine responsive megaloblastic anaemia. J Pediatr 1969; 74: 494-504

6 Fleming JC, Tartaglini E, Steinkamp MP, Schorderet DF, Cohen N, Neufeld $E J$. The gene mutated in thiamineresponsive anaemia with diabetes and deafness (TRMA) encodes a functional thiamine transporter. Nat Genet 1999; 22: 305-308
7 Bay A, Keskin M, Hizli S, Uygun H, Dai A, Gumruk F. Thiamine-responsive megaloblastic anemia syndrome. Int J Hematol 2010; 92: 524-526

8 Yuan G, Al-Shali KZ, Hegele RA. Hypertriglyceridemia: its etiology, effects and treatment. CMAJ 2007; 176: 1113-1120

9 Johansen CT, Hegele RA. Genetic bases of hypertriglyceridemic phenotypes. Curr Opin Lipidol 2011; 22: 247-253

10 Irwin JJ, Kirchner JT. Anemia in children. Am Fam Physician 2001; 64: $1379-1386$

11 Janus J, Moerschel SK. Evaluation of anemia in children. Am Fam Physician 2010; 81: 1462-1471

12 Hattersley AT, Bruining J, Shield J, Njolstad P, Donaghue KC. The diagnosis and management of monogenic diabetes in children and adolescents. Pediatric Diabetes 2009; 10: 33-42

13 Kucukemre Aydın B, Bundak R, Baş F, Maraş H, Saka N, Gunoz H et al. Permanent neonatal diabetes mellitus: Same mutation, different glycemic control with sulfonylurea therapy on long-term follow-up. J Clin Res Pediatr Endocrinol 2012; 4: 105-108

14 Akın L, Kurtoğlu S, Kendirci M, Akın MA, Karakükçü M. Does early treatment prevent deafness in thiamine-responsive megaloblastic anaemia syndrome? J Clin Res Pediatr Endocrinol 2011; 3: 36-39

15 Thornalley PJ, Babaei-Jadidi R, Al Ali H, Rabbani N, Antonysunil A, Larkin J et al. High prevalence of low plasma thiamine concentration in diabetes linked to a marker of vascular disease. Diabetologia 2007; 50: 2164-2170

16 Rabbani N, Thornalley PJ. Emerging role of thiamine therapy for prevention and treatment of early-stage diabetic nephropathy. Diabetes Obes Metab 2011; 13: 577-583

17 Ozdemir MA, Akcakus M, Kurtoglu S, Gunes T, Torun YA. TRMA syndrome (thiamine-responsive megaloblastic anaemia): a case report and review of the literature. Pediatr Diabetes 2002; 3: 205-209

18 Ricketts CJ, Minton JA, Samuel J, Ariyawansa I, Wales JK, Lo IF. Thiamine-responsive megaloblastic anaemia syndrome: long-term followup and mutation analysis of seven families. Acta Paediatr 2006; 95: 99-104

19 Crouzet-Ozenda Luci L, De Smet S, Monpoux F, Ferrero-Vacher C, Giuliano F, Sirvent $N$. Galactosemia associated with Rogers syndrome in a 10-month-old infant. Arch Pediatr 2011; 18: 54-57

20 Chahil TJ, Ginsberg HN. Diabetic dyslipidemia. Endocrinol Metab Clin North Am 2006; 35: 491-510 